\title{
The European AVIDICUS projects: \\ Collaborating to assess the viability of video-mediated interpreting in legal proceedings
}

Sabine Braun, University of Surrey

\section{Introduction}

This paper reports on a long-term European project collaboration between academic researchers and non-academic institutions with the aim of investigating the quality and viability of video-mediated interpreting in legal proceedings (AVIDICUS: Assessment of Video-Mediated Interpreting in the Criminal Justice System). The point of departure for this collaboration was the important role of legal interpreting in Europe, where police and courts require interpreters in well over 100 languages every day, making legal interpreters an essential part of the justice system whose efficient integration into legal proceedings is crucial to ensuring fairness and efficiency of justice.

This paper outlines the political background and rationale for this collaboration, explains the main aims and findings, and then summarises the key outcomes and assesses the value of this cooperation.

\section{Background and rationale}

The collaboration started in 2008 in response to the observation that videoconference links were widely used by police forces, courts, probation and prison services in Europe and that the use of interpreters in such video links ('videoconference interpreting') was rapidly increasing. In the UK, for example, the first pilot of 'virtual courts' (courts with video links to police stations for first hearings) in 2007 excluded cases requiring interpreters, whilst the second pilot in 2009 included such cases. The Multi-Annual European e-Justice Action Plan 2008-13 called for expanding the use of videoconferencing to speed up legal proceedings, especially cross-border proceedings, and to save money.

Furthermore, the Stockholm Programme of European justice and the Procedural Rights Roadmap led to the drafting and adoption of the European Directive 2010/64/EU on the right to interpretation and translation in criminal proceedings, which created a legal basis for using video links to gain access to qualified legal interpreters ('remote interpreting'). The Directive had to be implemented in the EU Member States by October 2013. In 2008, the Metropolitan Police Service (MPS) in London began to consider the use of remote interpreting in police interviews, whereby interpreters are linked to police stations from centralised interpreting hubs, in order to reduce interpreter travel costs, which constituted approximately one third of MPS's interpreting costs. In 2011, the remote interpreting project of the MPS remote interpretation project went live. 
However, until 2008, very little was known about the viability and quality of videomediated interpreting in legal proceedings. There was a high risk of potential miscarriages of justice through the combined effects of videoconferencing and interpreting. Relevant training for legal practitioners and interpreters was nonexistent. There was thus an urgent need for practice-oriented research and researchled practical guidance.

\section{Funding and partners}

It was clear that the questions at hand had to be addressed at European level and that a strategic partnership of different stakeholders was required. The Centre for Translation Studies at the University of Surrey therefore formed a European partner consortium consisting of research institutions with combined experience in legal interpreting and videoconference communication; representatives of the interpreting profession; the legal professions and the public sector. The consortium sought funding from the European Commission Directorate-General for Justice. Funding was obtained for three projects:

- 2008-11: AVIDICUS - Assessment of Videoconference Interpreting in the Criminal Justice Services, JLS/2008/JPEN/03

- 2011-13: AVIDICUS 2, JUST/2010/JPEN/AG/1558

- 2013-16: AVIDICUS 3 - Assessing the Implementation, JUST/2013/JPEN/AG/4553

The projects have been coordinated by the University of Surrey and have included, over the years, several research institutions (KU Leuven, Institut Télécom Paris and more recently the Universities of Alicante and Trieste); relevant governmental bodies (Ministry of Security and Justice of the Netherlands, Dutch Legal Aid Board, Local Police Antwerp); a lawyer from the Antwerp-based law firm Van der Mussele-Vanden Bosch; a lawyer-linguist with 30 years' experience as a Magistrate in the UK; and the Polish Society of Sworn and Specialised Translators.

\section{Work conducted: Aims, methods and findings}

This section gives an overview of work conduced to date, outlining the aims, methods and findings of each project and showing how they built on each other.

\section{AVIDICUS 1 (2008-11)}

Given the situation outlined above, the overall aim of the first AVIDICUS Project was to provide an initial assessment of whether the quality of video-mediated interpreting is suitable for criminal proceedings. The specific objectives of this project were:

1. To identify the situations in which video-mediated interpreting would be most useful from a criminal justice point of view;

2. To assess the reliability and quality of video-mediated interpreting through a comparative study of onsite and video-mediated interpreting;

3. To use the findings of this study to develop guidelines of good practice, and to design and pilot training modules for interpreters and legal practitioners. 
To achieve these objectives, the original AVIDICUS Project first conducted two surveys among legal interpreters and judicial institutions in Europe to elicit interpreter experience with video-mediated interpreting and institutional plans to use it. This enabled the partnership to identify the most pressing problems and the most likely future occurrences of video-mediated interpreting, which provided the basis for designing and conducting a series of experimental studies to compare the interpreting quality achieved with traditional methods of interpreting and in different configurations of video-mediated interpreting (videoconference interpreting and remote interpreting). The findings of this research were used to develop several training modules, which were piloted in stakeholder workshops, and to develop guidelines.

The work carried indicated a growing demand for all forms of video-mediated interpreting in all areas of criminal justice but also a considerable lack of knowledge among legal practitioners and interpreters about these modalities of interpreting. Equally important, the findings suggested that whilst basic practical problems with video-mediated interpreting may be resolved quickly through initial training and familiarization, the combined complexities of technological and linguistic-cultural mediation also create deeper-rooted behavioural and communication problems which may change the dynamics of legal communication. It was highlighted that further research would be required to investigate how this affects the specific goals of legal communication and to elicit adaptive strategies to mitigate such effects.

\section{AVIDICUS 2 (2011-13)}

AVIDICUS 2 built on the outcomes and the questions that arose from AVIDICUS 1. The aims of AVIDICUS 2 were:

1. To expand and improve the initial insights into video-mediated interpreting gained in AVIDICUS 1, especially by investigating

a. the impact of different variables such as training/familiarisation, experience and the quality of the technology on the interpreting quality;

b. the communicative dynamics of videoconference-based and interpreter-mediated criminal proceedings;

2. To disseminate current and emerging knowledge about the types, uses, benefits and challenges of video-mediated interpreting in criminal proceedings to national authorities, legal practitioners, interpreters and European citizens;

3. To improve training opportunities for legal practitioners and interpreters in the use of video-mediated interpreting.

The impact of the different variables was investigated through a further series of comparative studies, which replicated the design of the AVIDICUS 1 studies, involving the same interpreters but providing them with short-term training in video-mediated interpreting before they participated again, and using better equipment. The communicative dynamics was explored through an observational study of real-life videoconference-based, interpreter-mediated proceedings. The research was complemented by a series of individual and joint workshops for legal practitioners and interpreters, the enhancement and expansion of the original guidelines, and the 
production of a series of quick guides for legal practitioners, interpreters and European citizens.

The findings from AVIDICUS 2 create a complex picture, making it impossible to say without reservation that training, familiarization and the use of better equipment resulted in a clear performance improvement. Whilst some improvements and instances of adaptive behaviour (strategies) could be observed, a range of communication problems prevailed despite initial training and familiarization, and regardless of the quality of the technology. The analysis of the communicative dynamics in real-life proceedings furthermore revealed differences between traditional and video-mediated settings. Video-mediated interpreting seemed to entail a reduction in the quality of the intersubjective relations between the participants and a greater fragmentation of the discourse. The findings raised the broader question of whether videoconference-based, interpreter-mediated proceedings work best when they replicate as closely as possible the traditional face-to-face settings, e.g. by transferring known communication strategies and the spatial organisation of face-toface settings to the videoconference settings, or whether justice is better served when design solutions start from the main requirements for all legal communication-i.e. fairness and efficiency of justice. The research indicated that a replication of all aspects of face-to-face interpreting may not be the most effective solution for video-mediated proceedings and that further research needs to provide more detail on the factors that make videoconference solutions effective for bilingual communication.

\section{AVIDICUS 3 (2013-16)}

The questions relating to the effectiveness of bilingual videoconference communication in legal settings are currently being addressed in AVIDICUS 3, which has turned to the design and implementation of bilingual videoconferencing solutions. The main aim is to carry out a comprehensive assessment of the videoconferencing solutions currently used and/or planned in legal institutions across Europe in order to ascertain whether these solutions are fit for the purposes of conducting bilingual proceedings and integrating an interpreter.

This involves fieldwork in a number of European countries and interviews with representatives of different stakeholder groups to elicit information about such aspects as the configurations of bilingual videoconferencing that are required at present and in the foreseeable future; common patterns of physical and geographical distribution of the participants; types of equipment and transmission; room layout and positioning of the participants in relation to the videoconferencing equipment and to each other; mode(s) of interpreting; and videoconferencing literacy of the participants.

In accordance with the aim of the AVIDICUS projects as a whole, the research in AVIDICUS 3 will be complemented by the development of further guidance and training: One practical aim is to develop a comprehensive handbook on bilingual videoconferencing. A related practical aim is to make the training solutions developed in AVIDICUS 1 and 2 more accessible. Based on the insight that that onsite training can be costly or impractical, AVIDICUS 3 will develop an innovative method for using the medium of videoconference itself to deliver training in bilingual videoconferencing. 


\section{Assessment and conclusions}

Apart from the educational and policy impacts that this long-term project collaboration has made, its main impact arises from the contribution it makes to maintaining and improving the quality of legal interpreting and thus the quality of, and access to, justice for all citizens regardless of their needs for linguistic mediation. The collaborative approach has ensured the relevance of the research and the wide reach and dissemination of the results. It has enriched the knowledge base of the project partners and, by extension, the knowledge of the stakeholder groups that are represented in the partnership.

Through the collaboration, which has aimed to reconcile research findings and practical needs, the partnership has been able to generate a more comprehensive and more valuable outcome than an 'ivory-tower' approach. Whilst the project partners recognise the role of interpreting quality and are clear that a sufficient quality of interpreting performance is a conditio sine qua non which must override all considerations of cost savings, they are also clear that the advantages of videoconferencing, when appropriately used, must not be cursorily dismissed, especially at a time when the European effort to strengthen the rights of European citizens to translation and interpreting coincides-and sometimes competes - with financial constraints imposed on judicial and law enforcement institutions. This dual insight has been a major driving force and has led the partnership to design researchled but practical solutions that aim at mitigating current problems of video-mediated interpreting rather than stopping at the (scientific) insight that video-mediated interpreting is challenging.

The solutions will also be of interest to other public services, especially to healthcare and local government services, which encounter similar problems with access to qualified interpreters.

\section{References}

Braun, S., \& Taylor, J. (Eds) (2012). Videoconference and remote interpreting in legal proceedings. Antwerp: Intersentia.

Braun, S., \& Taylor, J. (Eds) (in preparation). Advances in Videoconferencing and interpreting in legal proceedings. Antwerp: Intersentia. 